\title{
Urgent Joint Observation of Aftershocks of the 1995 Hyogo-ken Nanbu Earthquake
}

\author{
Naoshi Hirata, ${ }^{1, *}$ Shiro Ohmi, ${ }^{2}$ Shin'ichi Sakai, ${ }^{1}$ Kei Katsumata, ${ }^{3}$ Satoshi Matsumoto, ${ }^{4}$ \\ Tetsuo Takanami, ${ }^{3}$ Akira Yamamoto, ${ }^{4}$ Takashi Iidaka, ${ }^{1}$ Taku Urabe, ${ }^{1}$ \\ Mayumi Sekine, ${ }^{1}$ Tooru Ooida, ${ }^{5}$ Fumihito Yamazaki, ${ }^{5}$ Hiroshi Katao, ${ }^{2}$ \\ Yasuhiro Umeda, ${ }^{2}$ Masao Nakamura, ${ }^{1}$ Norihiko Seto, ${ }^{1}$ \\ Takeshi Matsushima, ${ }^{6}$ Hiroshi Shimizu, ${ }^{6}$ and Japanese \\ University Group of the Urgent Joint Observation for \\ the 1995 Hyogo-ken Nanbu Earthquake \\ ${ }^{1}$ Earthquake Research Institute, The University of Tokyo, Bunkyo-ku, Tokyo 113, Japan \\ ${ }^{2}$ Disaster Prevention Research Institute, Kyoto University, Uji 611, Japan \\ ${ }^{3}$ Faculty of Science, Hokkaido University, Kita-ku, Sapporo 060, Japan \\ ${ }^{4}$ Faculty of Science, Tohoku University, Aoba-ku, Sendai 980, Japan \\ ${ }^{5}$ School of Science, Nagoya University, Chikusa-ku, Nagoya 464-01, Japan \\ ${ }^{6}$ Faculty of Science, Kyushu University, Higashi-ku, Fukuoka 812, Japan
}

\begin{abstract}
A disastrous earthquake with a magnitude of 7.2 hit the southern part of Hyogo Prefecture on January 17, 1995. The mainshock was located on an active fault of the Arima-Takatsuki-Rokko fault system. Its focal mechanism was consistent with a right-lateral strike-slip fault trending $\mathrm{N} 40^{\circ} \mathrm{E}$. Three days after the occurrence of the mainshock, we started to install a highly dense seismic array in and around the fault area of the quake. Two permanent regional seismic networks of more than 30 stations covered the entire area of $200 \mathrm{~km} \times 200 \mathrm{~km}$. The temporarily installed array of 27 stations spanned the fault area of $15 \mathrm{~km} \times 50 \mathrm{~km}$. All data were telemetered to a temporary observation center at Uji. We located about 3,100 aftershocks in real time for 1 month using an Internet connection between seismic networks. The aftershock area extended $70 \mathrm{~km}$ trending northeast to southwest. Hypocenters determined by the network were delivered automatically through the Internet. We found that the aftershock distribution was heterogeneous in space and time: seven clusters of hypocenters were identified and temporary variation in the rate of occurrence of aftershocks had a periodic component with periods of a half of day, 1 day, and 3 days, that are superimposed on decaying of the rate following Omori's law.
\end{abstract}

\section{Introduction}

A disaster earthquake with a magnitude of 7.2 hit the southern part of Hyogo Prefecture on January 17, 5:47 (JST), 1995 (Fig. 1). The quake was named the 1995 Hyogo-ken Nanbu earthquake by the Japan Meteorological Agency (JMA). Since the quake was shallow and very close to Kobe, one of the largest cities in southwestern Japan, more than 5,500 people were killed. The mainshock was located on an active fault system named the Arima-Takatsuki-Rokko fault system (Fig. 2). The strike-slip focal mechanism of the mainshock
(Japan Meteorological Agency, 1995) is consistent with a right-lateral strike-slip fault trending $\mathrm{N} 40^{\circ} \mathrm{E}$.

To understand the aftereffects of the mainshock on the stress field in the crust we observed aftershock activities and crustal deformation. To clarify concentration, redistribution, and relaxation of the stress after the mainshock we needed to observe precise aftershock distribution in space and time.

Three days after the occurrence of the mainshock, we started to install highly-dense seismic and GPS arrays in and near the fault area of the quake. We aimed to monitor seismic activity by 3-component seismometers in addition to the permanent seismic

Received August 4, 1995; Accepted February 21, 1996

* To whom correspondence should be addressed. 


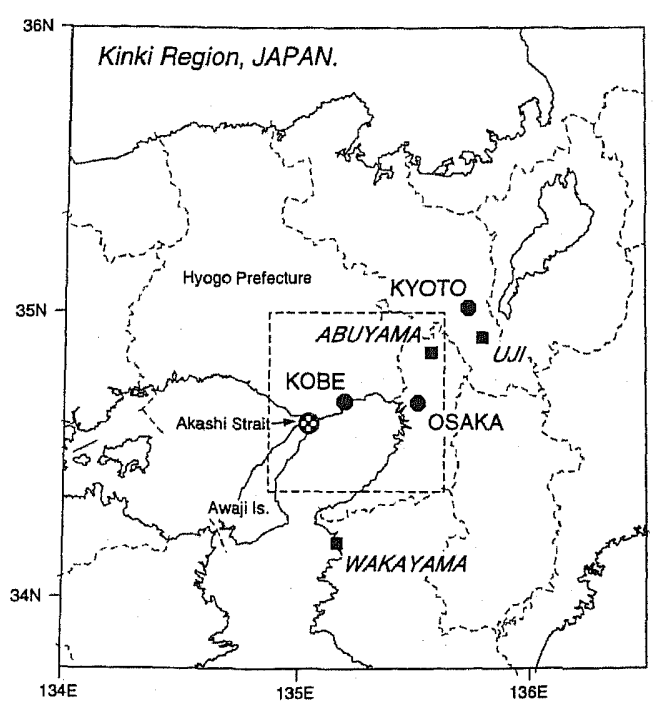

Fig. 1. Map of Kinki region showing the location of the 1995 Hyogo-ken Nanbu earthquake which is indicated by a patched circle. The dashed square indicates the area of Fig. 2.

networks of microearthquake observation. All data were telemetered to Disaster Prevention Research Institute (DPRI), Kyoto University, located in Uji. We determined the aftershock activity in real time using an Internet connection between seismic networks. The present study is a part of the joint observation of seismic and crustal activities after the quake, including seismic observations on land and sea, study of crustal deformation by GPS observation, and sediment sampling by piston coring off Awaji Island. We will report here on the aftershock observations by temporary seismic network and present preliminary results of the data analyses.

\section{Observation}

On January 20, 3 days after the mainshock, we initiated the program for the observation of after-effects of the 1995 Hyogo-ken Nanbu earthquake. We started to install field instruments at the same time, and on January 26,9 days after the mainshock, we located the first aftershock using this network. The network started to report seismic activity on January 28 and the observation lasted for 3 months. The seismic network consisted of temporary seismic stations in addition to the two permanent seismic networks. The center of one of

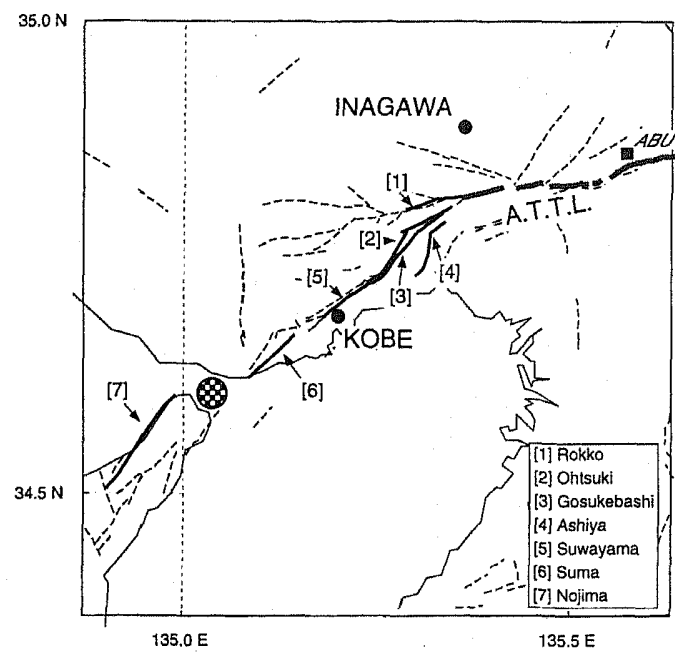

Fig. 2. Location of the 1995 Hyogo-ken Nanbu earthquake and distribution of active faults from Research Group for Active Faults in Japan (1991). Arima-Takatsuki-Rokko fault system consists of the Arima-Takatsuki tectonic line (ATTL) and active faults are denoted by solid lines. Dashed lines represent active faults in the studied area.

the permarent seismic networks is located in the Abuyama seismological observatory (Abuyama network), which is operated by DPRI, Kyoto University, and the center of the other network is in the Wakayama seismological observatory (Wakayama network), which is operated by Earthquake Research Institute (ERI), the University of Tokyo.

We deployed 27 temporary stations in the fault area of $15 \mathrm{~km} \times 50 \mathrm{~km}$ and combined 29 stations of two permanent seismic networks operated by DPRI and ERI (Fig. 3). Both permanent seismic networks were operated independently before and after the mainshock, and they reported seismic activities continuously. In addition to the routine operation of these networks, we connected the network more tightly to the temporary network for the present study (Fig. 4). All seismic wave data were digitized and processed by a work station system at each network center at Abuyama and Wakayama, and they were transferred to the temporary observation center at DPRI in Uji (hereafter referred to as $\mathrm{Uji}$ Center) through the Internet connection. The temporary stations started to transmit signals on January 26, and on February 14, all the 27 stations were connected to Uji Center. The Internet con- 


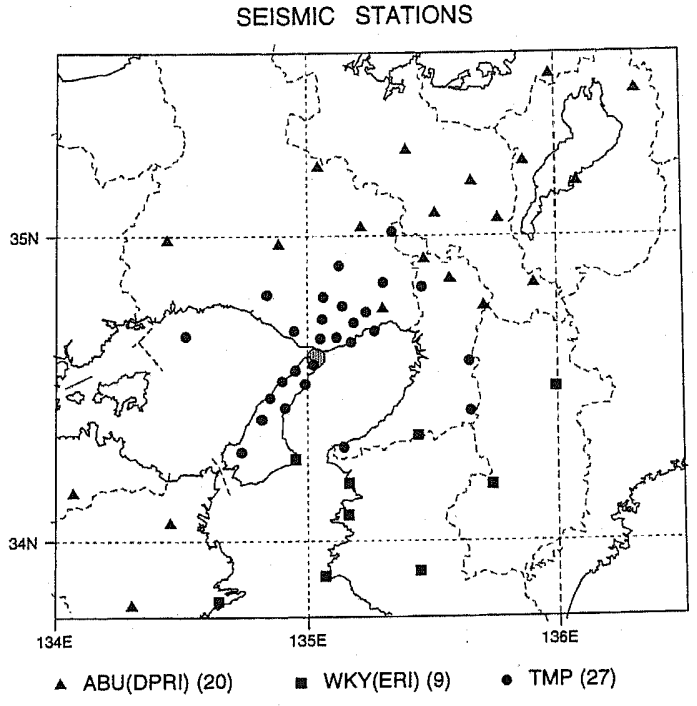

Fig. 3. Positions of seismometers used in the aftershock observation. We installed 27 temporary seismic stations and used two regional seismic networks including Abuyama (ABU) and Wakayama (WKY) seismic networks; they are indicated by solid circles, solid triangles and solid squares, respectively. Epicenter of the mainshock is a shaded circle in the Akashi Strait between Awaji Island and Kobe City.

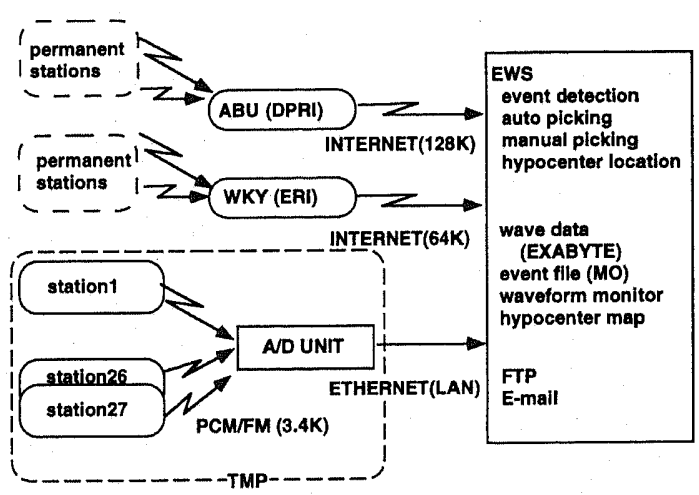

Fig. 4. Data flow diagram. We connected the data from the temporally installed network, ABU network, and WKY network by the Internet. The combined network is referred to as the urgent joint seismic network.

nection between the Abuyama network and $\mathrm{Uji}$ Center started on January 29 , and that between the Wakayama network and Uji Center on January
27. We used the win-format on the Internet (Urabe, $1991,1994)$ to send data from Abuyama and Wakayama networks to Uji Center. The format enabled us to use a packet transmission of time stamped seismic data using 128 or 64 kbit-persecond high speed data lines. All the data were processed digitally at Uji Center to detect and locate seismic events. We recorded 179-channel seismic data from 56 stations continuously and made a data file per event. In April we decreased the number of temporary stations from 27 to 10 , and stopped the operation in May. Since then, the seismic activities have been monitored and processed routinely by the permanent networks.

All the temporary operated stations were equipped with a 3-component seismometer with a natural frequency of 1.0 or $2.0 \mathrm{~Hz}$. The data were transmitted continuously in real-time by either frequency modulation (FM) or pulse code modulation (PCM) method. The frequency content for FM and PCM is up to $30 \mathrm{~Hz}$. The data were digitized at a sampling rate of $100 \mathrm{~Hz}$ at $\mathrm{Uji}$ Center and the data resolution was 12 bits.

The permanent seismic stations were equipped with $1.0 \mathrm{~Hz}$ seismometers (Kuroiso and Watanabe, 1977; Mizoue et al., 1983). The signals were digitized at a sampling rate of $200 \mathrm{~Hz}$ in the Abuyama network and $120 \mathrm{~Hz}$ in the Wakayama network. Our data format permitted us to use data of different sampling rates and data lengths simultaneously in the networks.

\section{Data and Hypocenter Determination}

The processing system at Uji Center enabled us to detect events, pick P- and S- phase arrival times, locate earthquakes, and estimate magnitudes in almost real time (Urabe, 1991). The system detected about 8,200 events in 1 month from January 26, of which 4,000 were judged as earthquakes. Among the earthquakes, 3,100 events were located. The system usually reported a hypocenter a few minutes after the occurrence of the earthquake and updated the data files automatically. The hypocenter information has been stored in an anonymous FTP site at ERI, which is open to anyone who wishes to gain access through the Internet. The detectability of small events depended primarily on the threshold of the amplitude ratio of signals to noise which we judged as an event. We totally adjusted the system parameters to locate microearthquakes with a magnitude of 1.0 or greater. We also stored data con- 


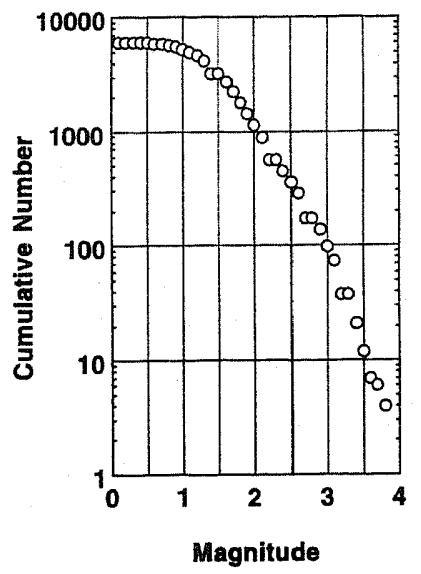

Fig. 5. Cumulative number $(N)$ versus magnitude $(M)$. The network uniformly detects events with a magnitude 1.5 or greater. The obtained $b$-value is 1.0 for $M>1.5$.

Table 1. Velocity structure used in hypocenter location.

\begin{tabular}{ccc}
\hline No. & $\begin{array}{c}\text { Thickness } \\
(\mathrm{km})\end{array}$ & $\begin{array}{c}\text { P-wave velocity } \\
(\mathrm{km} / \mathrm{s})\end{array}$ \\
\hline 1 & 3.0 & 5.5 \\
2 & 12.0 & 6.0 \\
3 & 15.0 & 6.8 \\
4 & half space & 7.9 \\
\hline
\end{tabular}

$V_{\mathrm{p}} / V_{\mathrm{S}}$ is assumed to be 1.73

tinuously in 8-mm digital tapes so that we were able to reprocess them if necessary. During the period from January 26 to May 12 , the array located more than 6,500 aftershocks. By looking at the magnitude-frequency distribution, we estimated that the array uniformly located aftershocks with a magnitude of 1.5 or greater (Fig. 5).

We used a velocity model that is used routinely at Wakayama Seismological Observatory. The model consists of three layers with a total crustal thickness of $30 \mathrm{~km}$ (Table 1), which is based on a refraction study of the region (Aoki and Muramatu, 1974). We used a location algorithm using a nonlinear inverse method (Hirata and Matsu'ura, 1987). Magnitudes were determined by maximum amplitude of P-wave with an empirical relation developed for microearthquakes (Watanabe, 1971).

\section{Aftershock Distribution}

The aftershock area extended $70 \mathrm{~km}$ trending northeast to southwest (Fig. 6). From this aftershock distribution and a focal mechanism solution of the mainshock (Japan Meteorological Agency, 1995), we can say that the mainshock occurred along a right-lateral strike-slip motion of a fault system with a strike of $N 40^{\circ} \mathrm{E}$, which corresponds to the Arima-Takatsuki-Rokko fault system. The system includes a fault in the northern part of Awaji Island where clear surface traces of slip of the mainshock were observed (Nakata et al., 1995).

The aftershock distribution shown in Fig. 6 consists of the events that occurred for about 1 month. According to the permanent seismic networks by DPRI and ERI, aftershock activities within $24 \mathrm{~h}$ after the occurrence of the mainshock were located south of the Arima-Takatsuki tectonic line (ATTL), spanning $50 \mathrm{~km}$ between $34^{\circ} 27^{\prime} \mathrm{N}$ and $34^{\circ} 45^{\prime} \mathrm{N}$. The aftershock area was then expanding beyond the ATTL to form a $70-\mathrm{km}-$ long linearly distributed zone. The northeast-southwest trending aftershock distribution is also clear in the JMA reported epicenters of aftershocks. We can therefore say that the mainshock was generated by the $50-\mathrm{km}$-long right-lateral strike-slip fault. The aftershock distribution is, however, not homogeneous in space and time, and enables us to clarify the detailed heterogeneity along the fault. The aftershock activity is highest in the southern part of the fault area and is low in the middle of the aftershock area where there is the hypocenter of the mainshock.

We divided the aftershock area into three zones from south to north. The southernmost zone, which is located beneath Awaji Island, is referred to as the Awaji zone. It is separated from the middle part of the aftershock area, which is located in Kobe City and is referred to as the Kobe zone, by an area where activity is very low beneath Akashi Strait. This area of low activity contains the hypocenter of the mainshock. The northernmost zone is an aftershock zone located north of the ATTL.

The aftershock activity decreases with time following Omori's law (Omori, 1894) in the Awaji and Kobe zones, while in the northern zone the seismicity starts to be active 2 days after the mainshock and does not follow the law. The activity of the northern zone is different from that in the Awaji and Kobe zones in also spatial distribution pattern: the area extends wider with time, and 


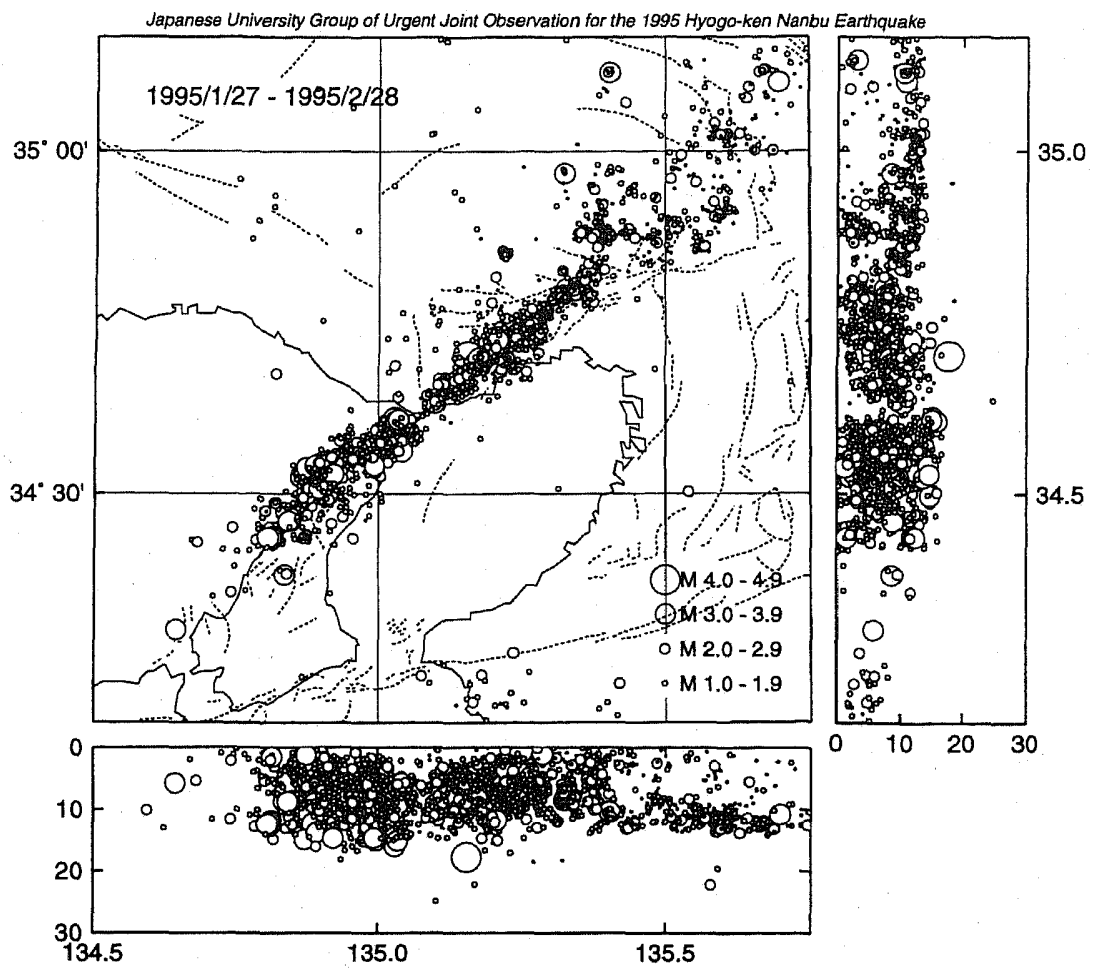

Fig. 6. Precise hypocenter distribution for the aftershocks determined by manually examined P- and S-arrivals for the period from January 27 to February 28. Aftershock activity was very low in the Akashi Strait where the mainshock had occurred. Dashed lines represent active faults (Research Group for Active Faults in Japan, 1991).

there are several local clusters in the area. In February, $70 \%$ of the aftershocks occurred in the Awaji or Kobe zones, while in March, $64 \%$ occurred there. However, in April, $42 \%$ of the total aftershocks occurred in the southern two zones, that is, relative seismicity increased in the northern zone. The activity is of a swarm type different from typical aftershocks. Therefore, we can surmise that the activities in the Awaji and Kobe zones are aftershocks directly related to the mainshock fault but the activity in the northern zone is a kind of induced seismicity of the occurrence of the main quake.

Next, we looked at the spatial distribution of the aftershocks in more detail. To determine where seismicity was most active, we counted the number of aftershocks with a magnitude of 1.0 or greater in each grid of $2^{\prime}$ latitude by $2^{\prime}$ longitude. A contour map showing the number of events is shown in Fig. 7, where we can see five distinct clusters in seismicity. Including the southernmost and northernmost activities, we labeled them A, B, C, D, $E, F, G$ (Fig. 7). The Awaji zone includes clusters $\mathrm{A}, \mathrm{B}$, and $\mathrm{C}$, the Kobe zone clusters $\mathrm{D}, \mathrm{E}$, and F, and the northern zone cluster $G$, respectively. Each cluster of activity occurred repeatedly in time and was separated by area where the seismicity was low.

\subsection{Awaji zone}

Cluster A forms the southernmost part of the aftershock area. No surface break in the fault of the mainshock was reported here. Clusters $\mathrm{B}$ and $\mathrm{C}$ are the most active of the clusters. Cluster $\mathrm{C}$ includes activity associated with the Nojima active fault where we observed clear surface displacements of up to $3 \mathrm{~m}$ due to the mainshock (Nakata et al., 1995). Cluster $\mathrm{C}$ is $10 \mathrm{~km}$ long in a northeast-southwest direction and is a few kilometers wide in a northwest-southeast direction. Although the cluster cor- 


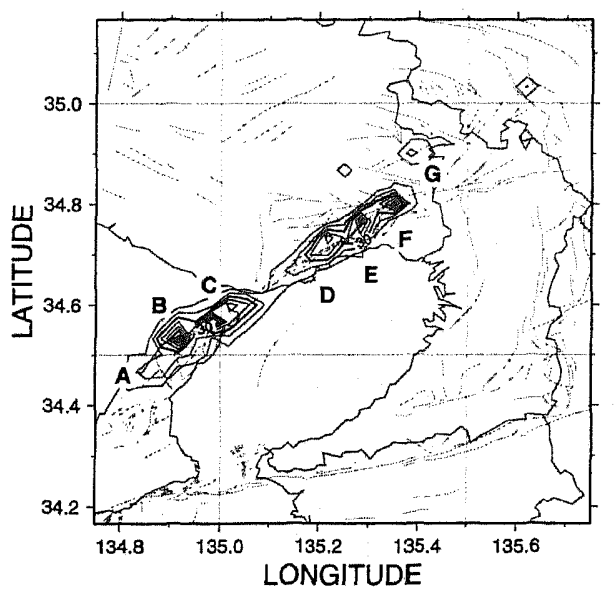

Fig. 7. Number of earthquakes in $2^{\prime} \times 2^{\prime}(3.6 \mathrm{~km} \times$ $3.6 \mathrm{~km}$ ) for the period from January $30,12: 00$ to February 23, 12:00. There are seven clusters of aftershocks, which are named A, B, C, D, E, $F$, and $G$. Thin lines represent active faults (Research Group for Active Faults in Japan, 1991). responds to one of the active faults observed at the surface, it has a wider distribution than the fracture zone of each fault. We can see that Cluster $\mathrm{C}$ has several groups with linear dimensions of a few kilometers. One noticeable distribution is a northwest-southeast trending group in the Akashi Strait (c- $c^{\prime}$ in Fig. 8). What we can conclude from Fig. 8 is that there are two directions of hypocentral distribution; a large scale northeast-southwest trending, which is parallel to the fault strike of the mainshock, and a small scale trend of northwestsoutheast distribution $5 \mathrm{~km}$ long and $1 \mathrm{~km}$ wide, which is perpendicular to the mainshock fault strike. The off-fault distribution is also seen in Cluster B on the west coast of Awaji Island (b-- $b^{\prime}$ in Fig. 8).

\subsection{Kobe zone}

The aftershock activity in the Kobe zone extends from the Arima-Takatsuki tectonic line (ATTL) to the coast of Kobe City. The southern end of the activity is clearly defined by a very inactive area beneath the Akashi Strait. In the Kobe zone we can also see several clusters. Among them, Clusters D,

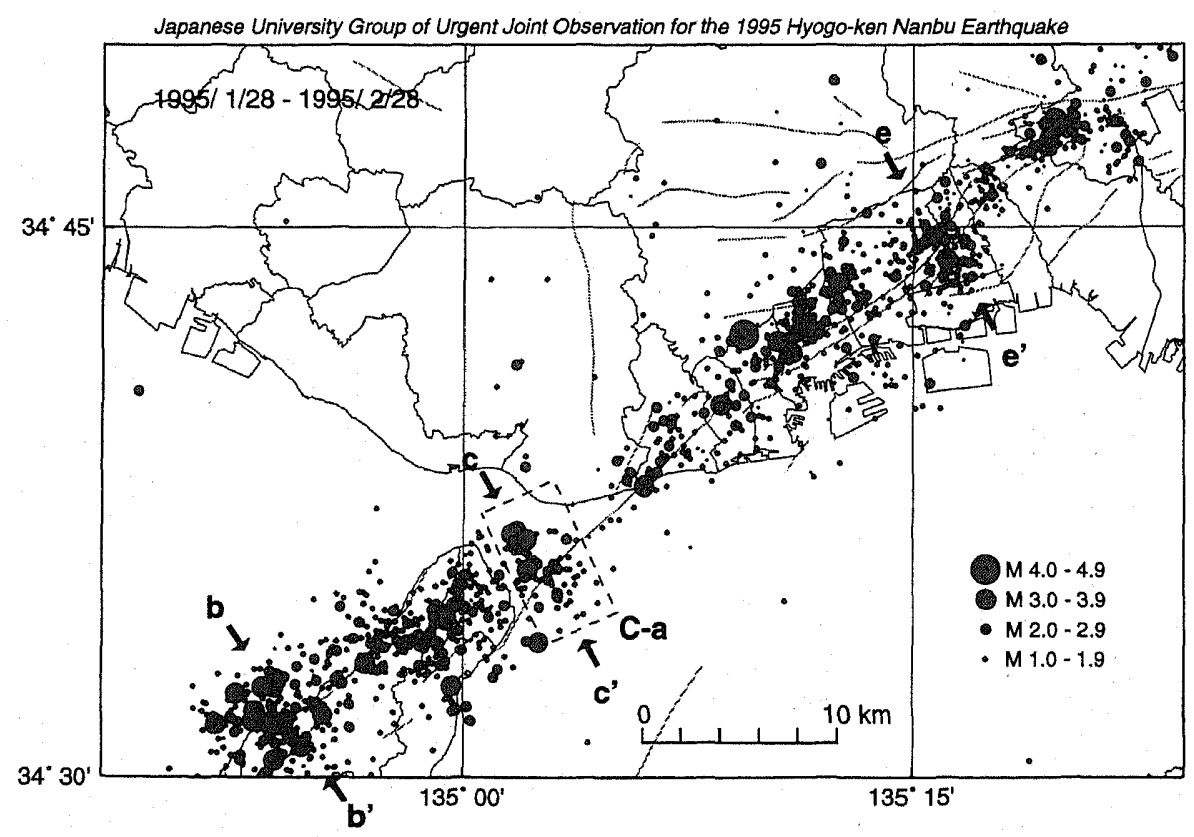

Fig. 8. Comparison between well-iocated aftershocks and active faults (Research Group for Active Faults in Japan, 1991). Dotted lines represent surface trace of active faults. In general, the aftershocks are distributed along the active fault. However, the activities are not exactly on the fault but are distributed in an area of a few kilometers wide. Also a linear distribution in northeast-southwest direction is seen in the Akashi Strait. 
$\mathrm{E}$, and $\mathrm{F}$ are dominant. These clusters are well correlated to the surface geology marked by the active fault system. Cluster D corresponds to the Suma and Suwayama Faults. The center of Cluster $\mathrm{D}$ is $10 \mathrm{~km}$ deep, which is deepest among clusters. Cluster E corresponds to the Gosukebashi Fault and the junction of Gosukebashi, Ashiya, and Suwayama Faults. Cluster F is located at the junction of the ATTL, Gosukebashi, and Ohtsuki Faults. In the Kobe zone, although the main trend of the distribution is northeast-southwest, several events also occurred southeast off the main trend $\left(\mathrm{e}-\mathrm{e}^{\prime}\right.$ in Fig. 8).

\subsection{Northern zone}

The aftershock distribution in the Northern zone occurs over a wider area in total than that in the Kobe and Awaji zones. It consists of many small clusters where activity sometimes increases with time. These activities include that which occurred near Inagawa Town, where swarm activity was reported a few months before the mainshock. The distribution is clearly different from that in the Awaji and Kobe zones: the distribution is more than $30 \mathrm{~km}$ wide in an east-west direction and is definitely not along one fault plane but is scattered within an area of $30 \times 30 \mathrm{~km}^{2}$. A temporary variation of rate of occurrence is also similar to swarm activities.

\section{Temporary Variation}

Since the Northern zone has different behavior in space and time, here we concentrate on the Awaji and Kobe zones. The rate of occurrence of the aftershocks decreased following the modified Omori's law with a $p$ value of 1 or slightly less: $p$ is 0.9 for $M$ of 2.5 or more (Matsu'ura et al., 1995). The decay rate is consistent with what is known for Japanese earthquakes that occur in land (Utsu, 1961). The largest aftershock with a magnitude of 5.4 occurred $2 \mathrm{~h}$ after the mainshock, the second $(M=5.2)$ occurred $4 \mathrm{~min}$ after the mainshock, and the third $(M=5.1)$ occurred a week later (Yoshikawa et al., 1995). These aftershocks seem to be small when compared to the magnitude of 7.2 for the mainshock. However, the total number and the decay rate of the occurrence of the aftershocks are within the family of moderate-sized earthquakes in Japan.

Apart from the general decaying behavior of the rate of occurrence of aftershocks, we observed periodic variations in the rate. We counted the aftershocks with different parameters. Figure 9 shows the variation in number of events with time: we selected events with a magnitude of 1.0 or greater which occurred within a 6-h-long time-window as well as in the aftershock area. We counted the number every hour by moving the time-window. The number is plotted at the end of the window in Fig.

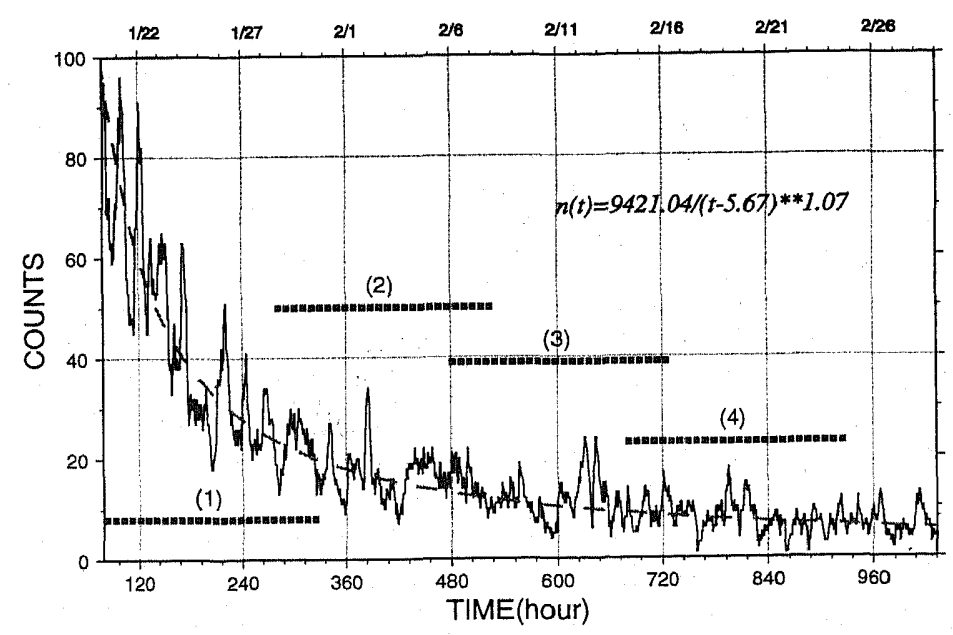

Fig. 9. Occurrence rate of aftershocks with time. The number of events during a 6-h period was counted every hour and plotted at the end of the period. Events of magnitudes of larger than 1.0 were analyzed. The general trend follows Omori's law and periodic variations are also seen. One-day component is dominant in the period (1). In later periods ( 3 and 4) 3-day component is dominant. 


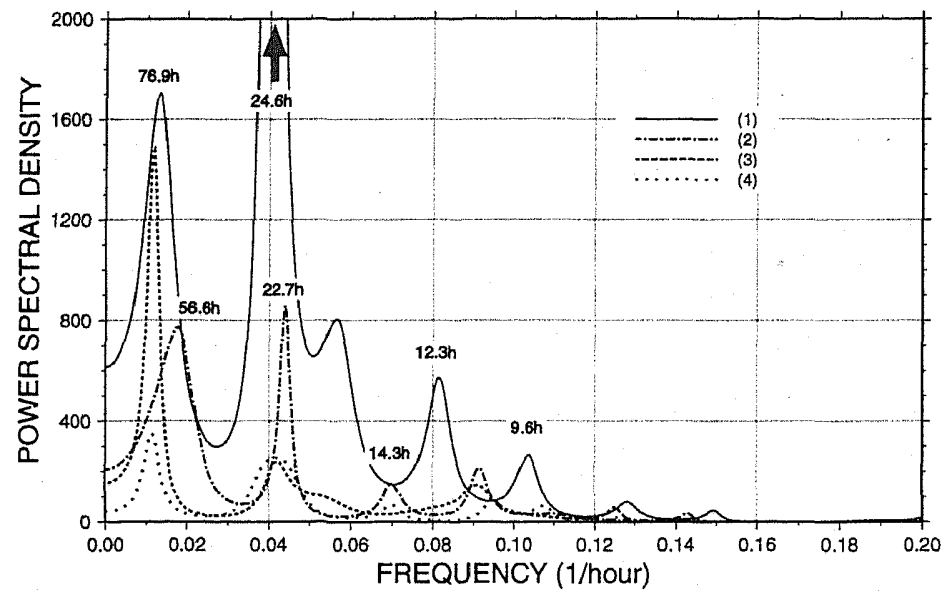

Fig. 10. Fourier spectra of the occurrence rate of aftershocks shown in Fig. 9. We calculate the power spectrum by the maximum entropy method. Spectra for 4 time-windows shown in Fig. 9 are calculated.

9. Because our temporary network started to report hypocenters regularly about 10 days after the mainshock, we incorporated data of hypocenters reported by the Wakayama network, which had an almost identical automatic processing system as that used in our temporary network. We clearly observe a cyclic variation with a period of about 1 day for the first 2 weeks after the mainshock. The detailed discussion of the periodic variation will appear elsewhere (Sekine and Hirata, in preparation), and only preliminary results will be presented here.

We examined the rate of occurrence of aftershocks and calculated the frequency spectrum by the maximum entropy method (Fig. 10). We can see that for about $400 \mathrm{~h}$ since the mainshock, the periodic variation of 1 day $(24.6 \mathrm{~h})$ is dominant and a half-day component $(12.3 \mathrm{~h})$ is also seen. After $400 \mathrm{~h}$, the 3-day $(56-77 \mathrm{~h})$ component is dominant. The 1-day component variation of the rate of occurrence is the fault-wide behavior, that is, in the phase where the rate is high, the number of events is large in both Awaji and Kobe zones.

The periods of a day and a half-day remind us of the effect of tidal force on the Earth's crust. However, we need further study to correlate the periodic variation with tidal effect. For example, because the detectability of the events depends on ground noise levels at seismographic stations, we need to examine if the periodic behavior is due to changes in the noise level or not. The peaks for the rate of occurrence in Fig. 9 for the first $400 \mathrm{~h}$ are located arourd midnight, which means that the aftershock activity is high in the time-window of 18:00 to $24: 00$ in a day. This suggests that the noise level is not the main contributor to the periodicity because the noise level is likely to be lowest from midnight to early in the morning. To see the effect of the detectability of the seismic network, we changed the threshold of the magnitude beyond which we counted aftershocks from 1.0 to 1.5 . We observed almost the same periodic pattern in rate between the two datasets. Even if we changed the threshold to 2.0, the peaks for the rate of occurrence with time still existed around midnight. Since the seismic network uniformly detected events of magnitude larger than 1.5, we can conclude that the periodicity is not due to the change in noise level.

\section{Discussion}

From highly-dense seismic observations in and around the fault area of the mainshock we could uniformly locate aftershocks with a magnitude of 1.5 or greater. The distribution revealed clustering of aftershocks in the fault area. This observation suggests that either the stress concentration after the mainshock or heterogeneity of strength of the crust occurs along the fault of the mainshock.

The observation that activity beneath the Akashi Strait is extremely low and that the hypocenter of the mainshock exists in this zone of low activity indicates that the zone is too weak to maintain strength against crustal deformation or that the stress was completely released in the area. Another 
possibility is that an aseismic slip existed there before the mainshock. Studies on the dynamic process of the fault slip during the mainshock revealed that, soon after an initial fracture occurred from the hypocenter of the mainshock at a depth of about $15 \mathrm{~km}$, the main fracture first propagated southwest- and up-wards to form, the largest dislocation beneath northern Awaji Island, which corresponds to the Nojima Fault on the surface. Then, the fracture moved northeastward to generate dislocation at depth beneath Kobe City (Ide et al., 1996; Yoshida et al., 1996).

Depths of the aftershocks extend from very shallow (about $1 \mathrm{~km}$ ) to $15 \mathrm{~km}$. The aftershocks beneath the coast of Kobe City were concentrated at a depth of around $10 \mathrm{~km}$. Although the absolute depth of the activity depends on a velocity model that we use for hypocenter location, the relative depths along the fault of the mainshock are clearly documented by our observation (Fig. 6): aftershock activity is shallow in the southernmost (Clusters A and B) and northern parts of the mainshock fault (Clusters $\mathrm{E}$ and F), while those occurring in the middle of the fault (Cluster $C$ and $D$ ) are relatively deep. In particular Cluster $D$ has very low activity at shallow depths down to $10 \mathrm{~km}$.
We can investigate the spatial distribution of heterogeneity along the mainshock fault in more detail: since our resolution of aftershock hypocenters is in the order of a few hundred meters, the hypocenter is well correlated to surface trace of a dislocation of displacement. One of the remarkable surface breaks is observed on the Nojima Fault. We actually located many aftershocks on the west coast of Awaji Island near the fault. However, as was mentioned in the previous section, hypocenters are distributed wider than $5 \mathrm{~km}$ and, for example, Cluster $\mathrm{C}$ includes both northeast-southwest and northwest-southeast trending linear distributions, which we refer to as sub-clusters. The sub-cluster may correspond to a secondary faulting induced by the main fracture, or the main fracture may include a zigzag faulting at least at shallow depth. Surface observation of active faults indicates that the fault system is right-step at the Akashi Strait and this is consistent with the sub-cluster (sub-cluster $\mathrm{C}$-a in Fig. 8) of northwest-southeast trend in the Akashi Strait if these fractures are conjugate faults controlled by an east-west compressional stress field.

We examined the focal mechanisms of some of the relatively large aftershocks. A preliminary investigation indicated that there are different focal

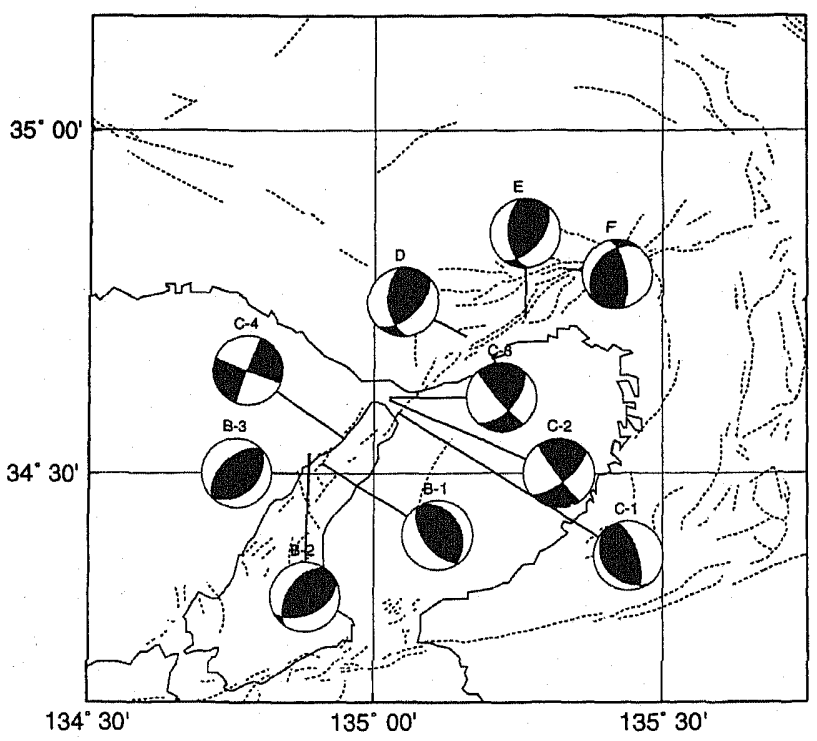

Fig. 11. Focal plane solutions of large aftershocks. Upper hemispheres are shown. Black shows area of push and white shows that of pull. Events in Kobe (Cluster D, E, and F) have a reverse faulttype mechanism with an east-west compression axis. On Awaji Island, aftershocks have both strikeslip and reverse fault-type mechanisms. The directions of compression axes are either northwestsoutheast or northeast-southwest, suggesting a complex pattern in stress field.

Vol. 44, No. 4, 1996 
solutions from a strike-slip solution, as in the case in the mainshock, to a reverse fault solution (Fig. 11). What is interesting is that reverse type solutions (B-1 and C-1 in Fig. 11) are obtained for events that occurred at the end of the sub-cluster with northwest-southeast trend. In sub-cluster $\mathrm{C}$-a, we have fault plane solutions of both strike-slip and reverse faults. Both solutions have a west-southwest-east-northeast compressional axis. However the direction of the compressional axis of those events that occurred at the west coast of Awaji Island (B-2, B-3) is northwestsoutheast, which is almost perpendicular to that of $\mathrm{C}-1$. This complex focal mechanism pattern is not fully understood at present and further systematic investigation is needed.

Although the physical mechanism by which sequential aftershocks are triggered and decay with time is not well-known, it seems to involve a combination of the action of the initial stress step on the mainshock fault with time-dependent strength, redistribution of stress by relaxation and creep in the weakened portions of the fault, and recovery of strength on the fault surface (Mikumo and Miyatake, 1979; Dieterich, 1986). The heterogeneity of the fault zone plays an important role in controlling the temporary behavior of a sequence (Kisslinger, 1993). The diffusion of pore fluids (Nur and Booker, 1972) and stress corrosion (Yamashita and Knopoff, 1987) have been proposed as essential contributors to the process. These processes may control the expanding activity north of the ArimaTakatsuki tectonic line (Cluster G).

Whether the aftershocks occur on the same fault surface that broke in the mainshock or in newly strained material in a zone around this surface is not easily resolved because we do not know the exact position of the fracture surface of the mainshock. In the present study, we clarified that aftershock activity is high near or around the area where the fault slip of the mainshock is large, while the aftershock is not active where the fault slip is large, and that the focal mechanism pattern along the mainshock area is complex.

These observations suggest that the mainshock generates a highly strained zone around the mainshock fracture surface and many aftershocks occur in the zone off the main fracture surface. This speculation does not exclude aftershocks on the same fault surface of the mainshock. Further extensive investigations on focal mechanisms of aftershocks as well as locations of aftershocks that occurred immediately after the mainshock are needed in order to solve the question.

\section{Conclusion}

Nine days after the occurrence of the 1995 Hyogo-ken Nanbu earthquake with a magnitude of 7.2 , we installed 27 temporary seismometers and telemetered them to the local observation center at Uji. At the same time, we gathered data from two permanent regional seismic networks with the Internet connection. We processed 179-channel seismic data from 57 stations. For 1 month of operation we located more than 3,100 aftershocks almost in real-time. The hypocenter information was delivered though the Internet to anyone who wished to gain access.

The aftershock distribution indicates clustered activity in space and time. We identified at least seven clusters in the aftershock area. The occurrence rate of the aftershock decays followed Omori's law in general but periodic variations were also found. The clustered activities were further divided into several sub-clusters with conjugate fault systems.

The observation that the area where aftershock activity is high corresponds to that where the slip during the mainshock is not large suggests that the mainshock generates a highly strained zone around the mainshock fracture surface and that many aftershocks occur in the zone off the main fracture surface. The idea is consistent with the complex pattern of focal mechanisms of aftershocks.

The hypocentral data used in the present study depend mainly on the automatic processed P- and $S$-arrival times. We are now re-examining the picking of arrivals to obtain more precise locations. The results will appear soon to clarify the exact relationship between surface trace of active faults and micro-aftershock distribution. The present study suggests that microearthquakes with at least a magnitude greater than 2 are distributed in areas that do not exactly coincide with the active fault, although the general distribution of the aftershocks, with a scale of a few kilometers, is well correlated to the active fault system.

This study was supported by many persons whom we thank very much. Kiyoshi Takano made efforts on preparing hypocenter data accessible on the Internet at ERI. Torao Tanaka directed the temporary observation center at DPRI (Uji Center). Norihiko Sumitomo and 
Masataka Ando helped us to establish the Uji Center. We also appreciate the help of Katsutoshi Yoshii, who organized staff at the Earthquake Prediction Research Center, ERI, for the present study. We thank Yoshiko Kotake, Sumiko Ogino, Kazuko Noguchi for their help in the present project. The present study is supported by the Ministry of Education, Science, Sports, and Culture under the program of the Urgent Joint Observation of the 1995 Hyogo-ken Nanbu Earthquake.

\section{REFERENCES}

Aoki, H. and I. Muramatu, Crustal structure in the profile across Kinki and Shikoku, Japan, as derives from the Miboro and the Toyama explosions, Zisin (J. Seismol. Soc. Jpn.), 27, 104-109, 1974.

Dieterich, J. H., A model for the nucleation of earthquake slip, in Earthquake Source Mechanics, Geophys. Monogr. Ser., Vol. 37, ed. S. Das, J. Boatwright, and C. H. Scholz, pp. 37-47, AGU, Washington, D. C., 1986.

Hirata, N. and M. Matsu'ura, Maximum likelihood estimation of hypocenter with origin time eliminated using non-linear inverse technique, Phys. Earth Planet. Inter., 47, 50-61, 1987.

Ide, S., M. Takeo, and Y. Yoshida, Source process of the 1995 Kobe earthquake: Determination of spatiotemporal slip distribution, Bull. Seismol. Soc. Am., 86, 547-566, 1996.

Japan Meteorological Agency, The 1995 HyogokenNanbu earthquake and its aftershocks, Rep. Coord. Comm. Earthq. Predict., 54, 584-592, 1995.

Kisslinger $C$., The stretched exponential function as an alternative model for aftershock decay rate, J. Geophys. Res., 98, 1913-1921, 1993.

Kuroiso, A. and H. Watanabe, On the telemeterd array system for microearthquake observation at Abuyama Seismological Observatory, Zisin (J. Seismol. Soc. Jpn.), 30, 91-109, 1977.

Matsu'ura, S. R., N. Hirata, and T. Urabe, Quasi-real-time watch of the aftershock activity change of HyogokenNanbu Earthquake- Prediction of Jan. $2523 \mathrm{~h} 16 \mathrm{~m}$ M4.7 aftershock, Rep. Coord. Comm. Earthq. Predict., 54, 600-607, 1995.

Mikumo, T. and T. Miyatake, Earthquake sequences on a frictional fault model with non-uniform strengths and relaxation times, Geophys. J. Astron. Soc., 59, 497-522, 1979.

Mizoue, M., M. Nakamura, N. Seto, and Y. Ishiketa, Three-layered distribution of microearthquakes in relation to focal mechanism variation in the $\mathrm{Kii}$ Peninsula, southern Honshu, Japan, Bull. Earthq. Res. Inst., Univ. Tokyo, 58, 287-310, 1983.

Nakata, T., K. Yomogida, J. Odaka, T. Sakamoto, K.
Asahi, and N. Chida, Surface fault ruptures associated with the 1995 Hyogoken-nanbu earthquake, J. Geogr., 104, 127-142, 1995 (in Japanese).

Nur, A. and J. R. Booker, Aftershocks caused by fluid flow?, Science, 175, 885-887, 1972.

Omori, F., On the aftershocks of the earthquakes, $J$. Coll. Sci. Imp. Univ. Tokyo, 7, 111-200, 1894.

Research Group for Active Faults in Japan, Active Faults in Japan: Sheet Maps and Inventories, revised ed., Univ. Tokyo Press, Tokyo, 437 pp., 1991.

Urabe, T., Method of seismic wave data telemetry, Zisin (J. Seismol. Soc. Jpn.), 44, 15-26, 1991.

Urabe, T., A proposal for a common format for multi-channel seismic wave data, Prog. Abstr. Seismol. Soc. Jpn., 2, 384, 1994.

Utsu, T., A statistical study on the occurrence of aftershocks, Geophys. Mag., 30, 521-605, 1961.

Watanabe, H., Determination of earthquake magnitude at regional distance in and near Japan, Zisin (J. Seismol. Soc. Jpn.), 24, 189-200, 1971.

Yamashita, T. and L. Knopoff, Models of aftershock occurrence, Geophys. J. Astron. Soc., 91, 13-26, 1987.

Yoshida, S., K. Koketsu, B. Shibazaki, T. Sagiya, T. Kato, and $Y$. Yoshida, Joint inversion of near- and far-field waveforms and geodetic data for the rupture process of the 1995 Kobe earthquake, J. Phys. Earth, 44, 437454, 1996

Yoshikawa, S., M. Nakamura, H. Kikuta, Y. Soshida, and Y. Ishikawa, Aftershock activity of Hyogoken-Nanbu Earthquake, Prog. Abstr. Seismol. Soc. Jpn., 2, B99, 1995.

\section{APPENDIX}

The present study was a cooperative study among many institutions that organized the Japanese University Group of Urgent Joint Observation for the 1995 Hyogo-ken Nanbu Earthquake. Participants of the present observation and their affiliation are as follows:

Tetsuo Takanami, Kei Katsumata, Hiroaki Takahashi (Hokkaido University)

Masahiro Kosuga, Masataka Watanabe, Tsuneaki Kawakami, Yoshiaki Oku

(Hirosaki University)

Kenshiro Tsumura, Katsunori Sasaki, Hiroyoshi Togashi, Akiko Hasemi

(Yamagata University)

Akira Yamamoto, Satoshi Matsumoto, Takeshi Nishimura, Koichi Nida, Hisashi Nakahara, Takuya Nishimura, Shinobu Ito, Kazuo Yoshimoto, Katsuhiko Shiomi, Tomomi Okada, Shigeki Aoki, Noriko Tsumura, Kazutoshi 
Watanabe, Guillermo Felix Rocco

(Tohoku University)

Akihiko Ito (Utsunomiya University)

Naoshi Hirata, Taku Urabe, Takashi Iidaka, Shin'ichi Sakai, Masao Nakamura, Norihiko Seto, Hiroko Hagiwara, Izumi Ogino, Shin'ichi Hashimoto, Kaname Sakai, Masaru Kobayashi, Toshio Haneda, Reiko Miura, Katsumi Miura, Shin'ya Tsukada, Mayumi Sekine, Kenji Uehira, Toshihiro Yoshihara (University of Tokyo)

Tooru Ooida, Takashi Okuda, Ryuichi Shichi, Masaru Nakamura, Naoyuki Fujii, Fumihito Yamazaki, Mamoru Yamada

(Nagoya University)

Hikaru Watanabe, Yasuhiro Umeda, Kiyoshi Ito, Hiroshi Katao, Shiro Ohmi, Kin'ya Nishigami, Takuo Shibutani, Kensuke Onoue, Makoto
Koizumi, Shigemitsu Matsuo, Kazuo Matsumura, Kunihiko Watanabe, Hiroo Wada, Yasuyosi Fujita, Yoshihiro Hiramatsu, Mamoru Nakamura, Haruo Horikawa, Yasuyuki Nakamura, Hiroaki Negishi, Akira Yamazaki, Glenda Besana, Shin Maruyama, Yoshiaki Fujiwara, Koichiro Obana, Akiko Ohigashi, Akihiro Motoki, Masaya Hirata, Youji Shimada, Hiroo Nemoto, Masanao Yamaoka, Akira Yamada, Yuko Kase

Keisuke Taniguchi (Kyoto University) (Kyoto University of Education) Shozo Kimura (Kochi University) Hiroshi Shimizu, Takeshi Matsushima, Kodo Umakoshi, Kazunari Uchida

(Kyushu University)

Shuichiro Hirano (Kagoshima University) 